\title{
Artikel
}

\section{Dit lijkt sprekend (nergens) op...}

\author{
De achtergrond van twee strafzaken over de sprekende gelijkenis van luchtdrukwapens en de \\ Wet wapens en munitie: Rb. Amsterdam 9 maart 2016, ECLI:NL:RBAMS:2016:1199 en Hof \\ Den Haag 25 mei 2016, ECLI:NL:GHDHA:2016:1469.
}

Prof. mr. H.J.B. Sackers*

\section{Inleiding}

Overtreding van de Wet wapens en munitie wordt snel geassocieerd met criminelen die met Kalasjnikovs zwaaien of die zich met illegale wapenhandel bezighouden. Daarmee wordt onrecht aan het hybride karakter van de wet gedaan. Naast de bestrijding van het illegale wapenbezit, normeert de wet ook het legale wapenbezit. Ongeveer 60.000 mensen bezitten een wapenverlof, meestal voor sportdoeleinden, verzamelingen, de jacht of re-enactment. Legaal wapenbezit leidt over het algemeen niet tot strafrechtelijk ingrijpen. ${ }^{1}$ Dat dit toch een enkele keer gebeurt, kan voor een deel te maken hebben met de complexiteit van wet- en regelgeving.

De kern van de strafbare gedragingen van de Wet wapens en munitie zijn de in artikel 2 opgesomde wapens. Deze wapens zijn in een viertal met Romeinse cijfers aangeduide categorieën in de wet ondergebracht. In categorie I zijn de wapens opgenomen zonder enig maatschappelijk nut. Alle gedragingen met deze wapens

* Prof. mr. H.J.B. Sackers is UHD straf(proces)recht en hoogleraar bestuurlijk sanctierecht aan de Radboud Universiteit. Van zijn hand verscheen in 2012 een monografie over de Wet wapens en munitie. Hij is als toetsingsdeskundige Wet wapens en munitie verbonden aan het Nederlands Register Gerechtelijke Deskundigen en tevens redacteur van dit tijdschrift. De schrijver is mr. M. van der Horst, advocaat-generaal bij het ressortsparket Den Haag, dankbaar voor de beschikbaar gestelde requisitoiraantekeningen.

1. Onderzoeksraad voor veiligheid, Wapenbezit door sportschutters, Den Haag, 2011. zijn verboden. In categorie II staan in hoofdzaak de (militaire) vuurwapens en andere 'gemeengevaarlijke' wapens. Deze wapens (voor een groot deel overgenomen uit de Vuurwapenwet 1919) behoren niet in handen van burgers te zijn. Dat geldt niet voor de (vuur)wapens van categorie III, waarvoor verlof mogelijk is voor bijvoorbeeld sportschutters en jagers. De minst gevaarlijke wapens zijn opgenomen in categorie IV. Het zijn de overige wapens, voor een deel afkomstig uit de Wapenwet 1890 , waarvoor in beginsel alleen een draagverbod geldt.

Met de keuze om de wapens in de wet op te nemen (en niet in een bijlage, zoals de wetgever bij de Opiumwet verkoos) heeft de praktijk het niet gemakkelijk. Het dwingt de officier van justitie tot tenlastelegging en tot bewijs van het juiste wapen, terwijl het de verdediging mogelijkheden biedt de omschrijving van het wapen en/ of de categorisering van het wapen te betwisten. Het is dan vervolgens aan de rechter om met hetgeen de inhoud van het dossier en het verhandelde ter zitting opleveren, bij een bewezenverklaring van de gedraging, het wapen en de juiste categorie van het wapen tot de juiste kwalificatie te komen. Dat dit bepaald geen sinecure is blijkt uit het feit dat menigmaal een beroep moest worden gedaan op een deskundige en zelfs dat het advies van de deskundige niet altijd garant staat voor een juiste oplossing van de wapenwetpuzzel. Een stiletto, valmes of vlindermes zijn, hoewel in de wet in een adem genoemd, juridisch drie geheel verschillende opvouwbare messen, die men vooral niet moet verwarren met het vilmes, het ballistisch mes, het werpmes of de dolk. 
Het in de wet opnemen van de wapens veroorzaakt nog een ander probleem. Hoe dient te worden omgegaan met 'nieuwe' wapens? Men denke bijvoorbeeld aan de kunststoffen (en dus niet detecteerbare) messen, die na 9/11 de markt ineens overspoelden. Deels heeft de wetgever dat willen ondervangen met ruime definities en omschrijvingen van 'vuurwapens' en 'voorwerpen bestemd voor het treffen van personen', deels door een nadere, maar ruimte overlatende duiding in de Regeling wapens en munitie. Als uiteindelijk vangnet zou artikel 2 lid 1, categorie I onder ten 7e moeten fungeren. ${ }^{2}$ Hierin staat dat als wapens in de zin van de Wet wapens en munitie tevens gelden "andere voorwerpen die een ernstige bedreiging van personen kunnen vormen of die zodanig op een wapen gelijken dat zij voor bedreiging of afdreiging geschikt zijn”.

\section{Luchtdrukwapens in het vangnet van de verboden wapens}

Deze vangnetbepaling sluit de wapens van de eerste categorie I af. De context van die categorie wordt bepaald doordat het merendeel van de voorwerpen in deze categorie de verboden handwapens betreft zoals die eerder waren opgenomen in de AMvB behorende bij de Wet tot wering van ongewenste handwapenen. De wetgever kenschetste in 1965 deze handwapens als 'nutteloos, hoogst gevaarlijk en voor de rechtsorde onaanvaardbaar'. Dit vond de wetgever in een later stadium ook van de pijl(punt)en en de katapult, want die werden aan categorie I toegevoegd, zodat die categorie "een systematische opsomming zal bevatten van alle verboden blanke wapens en enige andere absoluut verboden handwapens". ${ }^{3}$ Het is op zich voor te stellen dat ondanks de opsomming de behoefte bestond om een limitatief karakter daarvan te doorbreken met de vangnetbepaling. Zoals hierna nog aan de orde zal komen heeft de wetgever daarbij niet voor ogen gehad dat de praktijk ertoe zou leiden dat vreemde vissen in dat vangnet terecht zouden komen.

In het kielzog van hetgeen in de vangnetbepaling staat, worden in artikel 3 van de Regeling wapens en munitie (RWM) diverse voorwerpen aangewezen. Daaronder vallen (onder a): voorwerpen die voor wat betreft hun vorm en afmetingen een sprekende gelijkenis vertonen met vuurwapens of met voor ontploffing bestemde voorwerpen, met uitzondering van speelgoedvoorwerpen als bedoeld in de Richtlijn 2009/48/EG, en (onder b): voorwerpen vermeld op lijst a of lijst $b$ van de bij deze regeling behorende bijlage $\mathrm{I}$, alsmede niet in die bijlage genoemde voorwerpen die voor wat betreft hun

2. Min of meer gelijkluidend is het bepaalde in artikel 2 lid 1 categorie IV onder ten 7e.

3. Toegevoegd aan categorie I bij de herziening van de Wet wapens en munitie (Kamerstukken II, 1994-1995, 24 107, nr. 3). vorm en afmetingen daarmee een sprekende gelijkenis vertonen. ${ }^{4}$ Het zijn deze bepalingen die in twee recente strafzaken aan de orde zijn gekomen. Zij illustreren enerzijds de wonderlijke werking van de vangnetbepaling en strekken tegelijk tot waarschuwing aan goedwillende burgers die menen correct te handelen bij de aanschaf van een luchtdrukwapen.

\section{Luchtdrukwapens}

De casuistiek van de twee strafzaken is nagenoeg gelijk. Zowel de verdachte in de Amsterdamse zaak, als die bij het Haagse hof ${ }^{5}$ waren eerzame burgers ${ }^{6}$ die (los van elkaar) in 2009 een luchtdrukwapen via internet in het buitenland hadden besteld. In de Amsterdamse zaak kocht de verdachte een Huntingmaster, in de Haagse zaak ging het om een Benjamin Marauder. Beide luchtdrukgeweren werden bij binnenkomst op Schiphol in beslag genomen omdat zij vanwege de sprekende gelijkenis met een vuurwapen (kogelgeweer) onder categorie I ten 7e zouden vallen. Beide kopers viel een strafrechtelijke vervolging ten deel wegens het doen binnenkomen van een categorie I-wapen.

Voor de minder in de wapenwetgeving ingevoerde lezer dient direct ter toelichting te worden vermeld dat luchtdrukwapens in beginsel zijn toegestaan. In beginsel, want in artikel 2 lid 1 categorie IV staat onder ten $4 \mathrm{e}$ het verbod op "lucht-, gas- en veerdrukwapens, behoudens zulke door Onze Minister overeenkomstig categorie I, sub $7^{\circ}$, aangewezen die zodanig gelijken op een vuurwapen dat zij voor bedreiging of afdreiging geschikt zijn”. Valt een luchtdrukwapen niet onder categorie I, dan valt het onder categorie IV. Een luchtdrukwapen van categorie IV valt echter in een aanzienlijk milder regime. Voor een volwassene geldt alleen een draagverbod (kort gezegd: dat wapen mag men niet onverpakt op de openbare weg bij zich hebben). Een luchtdrukwapen mag verder zonder vergunning worden in- en uitgevoerd, overgedragen en voorhanden gehouden.

Het woord luchtdrukwapen verklaart zichzelf: het wapen verschiet een projectiel, de diabolo (een loden kogeltje), dat het wapen verlaat door middel van samengeperste lucht, een pompsysteem, zuigersysteem of door middel van samengeperst gas. Anders dan bij vuurwapens vindt geen scheikundige ontploffing plaats. Veelal worden luchtdrukwapens gebruikt voor recreatieve of

4. Na wijziging van artikel 3 RWM, Stcrt. 2001, 230

5. Gemakshalve zal van het 'Haagse hof' of de 'Haagse zaak' worden gesproken, ook al diende deze strafzaak voordien bij het Hof Amsterdam.

6. In die zin dat beide first offenders waren, de Amsterdamse verdachte al veertig jaar zonder problemen de schietsport beoefende en om meerdere redenen groot belang erbij had om de wet niet te overtreden, maar vooral eerzaam geacht wilde zijn gelet op zijn (voor hem) belangrijke academische en professionele reputatie. 
sportdoeleinden. ${ }^{7}$ Dit verklaart de grote diversiteit in luchtdrukwapens; ze zijn in alle soorten en maten verkrijgbaar.

Los van de vraag naar de gelijkenis tussen een luchtdrukwapen en een vuurwapen, heeft de regelgever bij voortduring geworsteld met de luchtdrukwapens. ${ }^{8}$ De zwaardere luchtdrukwapens (met een hoge kinetische mondingsenergie) waren in het verleden verboden, maar dit verbod kon bij gebreke aan fatsoenlijke testapparatuur bij de politie niet worden gehandhaafd. Recent besloot de staatssecretaris om een nieuw (en een zijns inziens wel handhaafbaar) verbod in te voeren voor luchtdrukwapens met een schotkracht van 80 joule of meer. ${ }^{9}$ Er is (om de complexiteit aan te geven) een afzonderlijke regeling tot stand gekomen voor de lichtere luchtdrukwapens (de zogenoemde airsoftwapens). ${ }^{10}$

Luchtdrukwapens zijn dus toegestaan, tenzij ze op een vuurwapen gelijken. In de hier besproken strafzaken hebben beide verdachten als volgt geredeneerd. Een categorie IV-wapen mag zonder vergunning worden ingevoerd. Gelet echter op de complicatie dat de luchtdrukwapens niet op een vuurwapen mogen gelijken, hebben de verdachten destijds dan ook zo goed mogelijk onderzoek gedaan en zich ervan vergewist dat het importeren van dit luchtdrukwapen volgens de Nederlandse wet toelaatbaar was. De Amsterdamse verdachte verklaart dat hij ook op lijst b heeft gekeken en contact met de douane heeft gehad. Hoewel hij geen jurist is, stelt hij als wetenschapper logisch te kunnen denken en beschouwt hij zich niet als 'argeloze koper'. Hij heeft weloverwogen voor de Huntingmaster gekozen om aan de goede kant van de wet te blijven. De rechtbank spreekt hem (na twee zittingen) vrij; het Openbaar Ministerie heeft in de vrijspraak berust.

Voor vrijspraak ging ook de verdachte in de Haagse zaak. Alleen hij heeft een wat langere rechtsgang moeten bewandelen. Zijn zaak begint in 2010 met een veroordeling door de rechtbank. ${ }^{11}$ De veroordeling is in beslissende mate gebaseerd op de verklaring van een zoge-

7. Bij luchtdrukwapens wordt een onderscheid gemaakt tussen het schieten met een luchtgeweer en met een luchtpistool. Beide wapens werken meestal met een cilinder met CO2-gas of met perslucht. Het gascilindertje wordt doorgaans in de kolf van het wapen ingebracht; het is te vergelijken met hetgeen voor de druk in de slagroomspuit is ingebracht. De diabolo heeft een diameter van 4,5 mm (kaliber .177) en is een halve gram zwaar. Het luchtgeweer mag voor sportdoeleinden maximaal 5,5 kilogram wegen, het luchtpistool maximaal anderhalve kilogram. Op bijna alle door de KNSA erkende schietsportverenigingen bestaat de mogelijkheid om met luchtdruk te schieten, gewoonlijk over een afstand van tien meter. Schieten met luchtdruk is een relatief goedkope discipline, en wordt vaak als eerste kennismaking met de schietsport beoefend.

8. In de Kamer is over de toelaatbaarheid van luchtdrukwapens een stevig debat gevoerd. Het resulteerde in de toezegging van de minister dat bij een hercodificatie van de wapenwetgeving ook ruimte zou zijn voor een nieuw voor te stellen Wet op de luchtdrukwapens (Bijlage Handelingen II 1963-1964, p. 7719). Die hercodificatie heeft uiteindelijk plaatsgevonden, maar een afzonderlijke wet voor luchtdrukwapens is er nooit gekomen.

9. Kamerstukken I/ 2015-2016, 33 033, nr. 18

10. Artikel $17 \mathrm{a}$ tot en met artikel $17 \mathrm{~g}$ RWM, ingevoerd op 7 januari 2013 , Stcrt. 2013, 610. Een uitwerking van deze regels is te vinden in paragraaf 2.9 Circulaire wapens en munitie 2015-II, Stcrt. 2015, 41295.

11. Rb. Amsterdam 22 november 2010 (niet gepubliceerd). noemde 'taakaccenthouder wapens en munitie'. Deze politiefunctionaris was tot de bevinding gekomen dat van sprekende gelijkenis sprake was. In hoger beroep leek het tij te keren. Inmiddels was het luchtdrukwapen door een NRGD-deskundige ${ }^{12}$ bekeken en die was tot een andere conclusie gekomen: de Benjamin Marauder vertoont geen sprekende gelijkenis met een vuurwapen. Zijn bevindingen, voorafgaand aan de zitting met OM en verdediging gedeeld, brachten de AG (en in diens voetspoor de verdediging) tot het standpunt dat vrijspraak moest volgen. Wellicht waren de bevindingen van de deskundige zodanig concludent dat deze niet aan enige twijfel onderhevig waren. Feit is dat de deskundige niet door het hof werd gehoord, noch zijn rapport in de zitting ingebracht, noch vermeld in een pleitnota. Het hof veroordeelde, opnieuw op basis van het procesverbaal van de 'taakaccenthouder' ${ }^{13}$ Beroep in cassatie volgde, maar tevergeefs. Ook al bevond het rapport van de deskundige zich bij de cassatieschriftuur, de Hoge Raad hield (ondanks de andersluidende conclusie van de AG) vast aan het proces-verbaal van de zitting bij het hof, waaruit niet bleek dat aldaar de deskundigheid van de 'taakaccenthouder' was betwist. ${ }^{14}$ Ondanks dat zowel rechtbank als hof volstonden met een schuldigverklaring zonder straf ${ }^{15}$, werd prompt herziening gevraagd. Het herzieningsverzoek bevatte niet alleen het eerdergenoemde deskundigenrapport, veiligheidshalve had de verdediging nog een tweede deskundige (van het NFI) geraadpleegd en ook diens (gelijkluidende) rapport ingebracht. Het herzieningsverzoek werd gehonoreerd. De Hoge Raad oordeelde dat een ernstig vermoeden was ontstaan dat het hof, ware het met de inhoud van de deskundigenrapporten bekend geweest, tot vrijspraak zou hebben besloten. ${ }^{16}$

De zaak is na verwijzing opnieuw behandeld door het Hof Den Haag. Dat besloot dat het voor een juist oordeel noodzakelijk was om het wapen op de zitting te hebben. En dan krijgt de zaak andermaal een verassende wending. De AG moet het hof in mei 2016 melden dat het wapen op last van het Amsterdamse parket inmiddels was vernietigd, vermoedelijk omdat men geen weet had van de succesvolle herziening. Op 25 mei 2016 wijst het hof arrest: vrijspraak. Het OM, kennelijk ontevreden over de magere oogst, heeft inmiddels beroep in cassatie ingesteld

\section{Magere oogst}

Naar de uitkomst van de twee zaken is uitgekeken; zij hebben echter niet opgeleverd wat aan rechtsvragen op

12. Nederlands Register Gerechtelijke Deskundigen (in casu op het domein Wet wapens en munitie).

13. Hof Amsterdam (zitting houdend in Arnhem) 4 november 2011 (niet gepubliceerd).

14. HR 19 november 2013, ECLI:NL:HR:2013:1352, NJ 2014/39 m.nt. Borgers. Over het voorgevallene ter zitting van het hof zie punt 5.2 en 6.1-2 van de conclusie van de A-G Machielse voor dit arrest.

15. Maar wel met onttrekking aan het verkeer van het wapen.

16. HR 24 maart 2015, ECLI:NL:HR:2015:712, NJ 2015/697. 
het gebied van de wapenwetgeving was uitgelokt. Het Amsterdamse vonnis is vooral interessant vanwege het lex certa-beginsel dat hierna verder wordt besproken in de annotatie van Nan. Het Haagse arrest leert dat de minister weliswaar de voorwerpen van categorie I ten 7e 'aanwijst' (en die aanwijzing in artikel 3 RWM heeft gedaan), maar dat het de rechter is die beoordeelt of van sprekende gelijkenis sprake is. Het gaat immers om een bestanddeel uit de tenlastelegging. Het begrip 'sprekende gelijkenis' vergt een normatieve invulling, die tot het domein van de rechter behoort. Dus beoordeelt de rechter aan de hand van de bewijsmiddelen of het voorwerp uit de tenlastelegging sprekende gelijkenis vertoont met een echt vuurwapen. ${ }^{17}$

Een van de kwesties die rondom de dreigvoorwerpen onbeantwoord bleef was de vraag of er een onderscheid bestaat tussen voorwerpen die een ernstige bedreiging van personen kunnen vormen, en voorwerpen die zodanig op een wapen gelijken dat zij voor bedreiging of afdreiging geschikt zijn. De zinsconstructie van categorie I ten $7 \mathrm{e}$ (alsmede de oorspronkelijke redactie van artikel 3 RWM $)^{18}$ doet vermoeden dat het om twee soorten voorwerpen gaat. Hoewel het goed mogelijk is om een voorbeeld te geven van een voorwerp dat een ernstige bedreiging van personen vormt, maar geen voorwerp dat door zijn sprekende gelijkenis met een vuurwapen voor bedreiging of afdreiging geschikt is, lijkt de redenering vaak te zijn dat een voorwerp dat sprekende gelijkenis met een vuurwapen vertoont daardoor het karakter van een dreigvoorwerp krijgt. Veel rechtspraak hierover is niet voorhanden, maar uit de weinige uitspraken die er zijn valt af te leiden dat bij een voorwerp dat geen sprekende gelijkenis met een vuurwapen vertoont, de rechter enigszins objectief beoordeelt of een gemiddeld persoon daarmee ernstig kan worden bedreigd. Aan het adjectief 'ernstig' lijkt weinig of geen betekenis toe te komen. De kernvraag is de vraag hoe de rechter de sprekende gelijkenis beoordeelt.

\section{De sprekende gelijkenis}

Uit de toelichting bij de inhoudelijke wijziging van artikel 3 RWM blijkt dat de regelgever de volgende handvatten voor de beoordeling van de sprekende gelijkenis heeft willen bieden. ${ }^{19}$ De essentiële parameters zijn de vorm van het voorwerp en de afmetingen, waarbij de afmetingen ondergeschikt zijn aan de vorm. Een verschil van 'enkele centimeters' is niet belangrijk. Ook de

17. Zie de conclusie van de AG Bleichrodt voor HR 26 april 2016 ECLI:NL:HR:2016:735. Eigenlijk viel het primaat van de rechter al uit oude Kamerstukken af te leiden (Kamerstukken II, 1964-1965, 7719, nr. 6, p. 2).

18. Aanvankelijk leek een onderscheid af te leiden uit de aard van de voorwerpen die op lijst a en op lijst $b$ van de bij de regeling behorende bijlage I waren geplaatst (zie achtereenvolgens Stcrt. 1996, 245; Stcrt. 1997, 129; en Stcrt. 2001, 230). Wat daarvan verder zij, de lijsten zijn sedert 2008 niet meer bijgehouden, waren overigens nauwelijks te vinden, en zijn inmiddels vervallen.

19. Stcrt. 2001, 230. kleur is niet van belang. Uit de zin "het voorwerp behoeft niet een gelijkenis te vertonen met één specifiek vuurwapen" valt af te leiden dat de gelijkenis minder sprekend behoeft te zijn, dan het spraakgebruik aan de uitdrukking toekent. Dit noopt de rechter tot het maken van een vergelijking. De meest zuivere vergelijking komt tot stand door een visuele schouw van het voorwerp en het vuurwapen. Nu komt het (niet alleen in de Haagse zaak, maar regelmatig) voor dat ofwel het voorwerp, ofwel het vuurwapen waarmee gelijkenis is, niet (meer) beschikbaar is. Bovendien zal de verdediging niet voetstoots willen afgaan op wat het proces-verbaal vermeldt. ${ }^{20}$ Soms zullen foto's een oplossing bieden, maar die kunnen juist bij de sprekende gelijkenis verwarring zaaien. Een andere mogelijkheid is het inschakelen van een deskundige (zoals in het Haagse arrest) die de voor het maken van de vergelijking noodzakelijke voorlichting geeft. Lukt dat allemaal niet, dan ligt vrijspraak voor de hand. ${ }^{21}$

Uiteindelijk zal de rechter moeten beslissen, maar over de vraag hoe die beslissing tot stand komt bestaat in de feitenrechtspraak onduidelijkheid. Globaal geeft die rechtspraak drie benaderingen te zien.

De eerste visie zou men de abstracte toetsing kunnen noemen. Daarbij wordt bezien of het voorwerp een sprekende gelijkenis vertoont met een vuurwapen in het algemeen. In deze benadering kijkt men niet naar een sprekende gelijkenis met een bepaald vuurwapen, maar bijvoorbeeld hoe een slachtoffer bij een bedreiging op het voorwerp heeft gereageerd of zou kunnen reageren. Onder meer het Amsterdamse vonnis gaat daarvan uit. ${ }^{22}$ In de tweede visie (de concrete toetsing) gaat het om het vaststellen van de sprekende gelijkenis met een concreet aangeduid vuurwapen. Ook die benadering is in de rechtspraak terug te vinden. ${ }^{23}$ In de derde benadering (de gemengde toetsing) wordt eerst bezien of sprekende gelijkenis bestaat met een bepaald bestaand vuurwapen, en vervolgens of de niet-functionele onderdelen van het voorwerp erop zijn aangebracht (kennelijk) om het op een echt vuurwapen te laten gelijken (waardoor het voor bedreiging of afdreiging geschikt is). Of deze visie heersend is valt niet te zeggen, wel dat de feitenrechters in (niet overtuigende) meerderheid deze lijn volgen. ${ }^{24}$ Soms echter lijkt het erop dat de feitenrechter geen

20. Voor het opmaken van een dergelijk proces-verbaal dat voldoende betrouwbaar is, is deskundigheid noodzakelijk; zie Rb. Gelderland 2 november 2015, ECLI:NL:RBGEL:2015:6687 dat vrijspreekt, nu “niet door een daartoe aangewezen deskundige is vastgesteld dat deze voorwerpen daadwerkelijk een stiletto en valmessen in de zin van de WWM betreffen". Enigszins vaag is wie de rechtbank met een daartoe aangewezene bedoelt.

21. Hof Den Haag 12 april 2010, ECLI:NL:GHSGR:BM4404.

22. Enkele andere voorbeelden: Rb. Rotterdam 22 november 2006, ECLI:NL:RBROT:2006:AZ3033, NJFS 2007/60; Hof Amsterdam 24 oktober 2012, ECLI:NL:GHAMS:2012:BZ8602; Rb. Noord-Nederland 22 april 2013, ECLI:NL:RBNNE:2013:BZ8228.

23. Enkele voorbeelden: Rb. Leeuwarden 1 oktober 2012, ECLI:NL:RBLEE: 2012:BX8795; Rb. Zwolle-Lelystad 22 november 2012, ECLI:NL:RBZLY: 2011:BV2702; Rb. Limburg 18 juni 2013, ECLI:NL:RBLIM:2013:3877.

24. Een duidelijk voorbeeld is Hof Amsterdam 8 mei 2013, ECLI:NL:GHAMS:2013:BZ9977. Het is ook de lijn (het stappenplan) die de deskundige in het Haagse arrest volgt. 
enkele leer volgt en (wellicht bij gebreke aan een verweer) voetstoots het proces-verbaal volgt. ${ }^{25}$

Welke visie de Hoge Raad voorstaat is niet duidelijk. Het in deze discussie vaak genoemde arrest over de paintballmarkers gaat (op de keper beschouwd) daarop niet in. ${ }^{26}$ Die kans kreeg de Hoge Raad wel in de Benjamin Marauder-zaak, maar ook daarin laat de Hoge Raad zich niet uit over de sprekende gelijkenis. Dit gaf annotator Borgers aanleiding om te verzuchten dat het arrest vooral opvalt door de zaken die de Hoge Raad niet aan de orde stelt, zoals "de niet onbelangrijke kwestie van de sprekende gelijkenis bij luchtdrukwapens die nu eenmaal snel een zekere gelijkenis met een vuurwapen vertonen". Kennelijk vindt de Hoge Raad dit te feitelijk voor de cassatierechtspraak, hetgeen de deur openzette voor het Haagse Hof om in zijn arrest van 25 mei 2016, in afwijking van het standpunt van de AG, te opteren voor de concrete toetsing, zonder dat het hof zijn keuze nader heeft toegelicht. In dat opzicht is het Amsterdamse vonnis op dit punt duidelijker, waar de rechtbank overweegt dat zich een zekere consensus in de feitenrechtspraak ontwikkelt dat bij het vaststellen van sprekende gelijkenis moet worden uitgegaan van de gemiddelde mens, eerder dan wat deskundigen (nadat strafvervolging is aangevangen) vertellen over niet-functionele onderdelen van het voorwerp ${ }^{27}$ waarmee de fabrikant het voorwerp kennelijk het uiterlijk van een vuurwapen heeft willen geven.

\section{De sprekende gelijkenis is failliet}

Het is, aan het einde van deze beschouwing gekomen, niet zozeer de vraag welke toetsing van de sprekende gelijkenis nu de juiste is, al lijken ondanks het arrest van het Haagse hof de aanhangers van de abstracte toetsing terrein te verliezen. Het is veeleer de vraag in hoeverre het verbod op voorwerpen met een sprekende gelijkenis rechtens nog stand kan houden. Hiervoor kwam al aan de orde dat aan de inhoud van de lijsten behorende bij de bijlage van artikel 3 RWM geen actualiteit meer kan worden ontleend. Ze zijn dan ook inmiddels vervallen. Dit gebeurde bij de implementatie van de Speelgoedrichtlijn, die al het gekeurmerkt speelgoed van strafbaar2016:2675

26. HR 9 oktober 2012, ECLI:NL:HR:2012:BX4096, NJ 2012/592. Het ging om de vraag wat paintballmarkers zijn en of deze onder categorie I onder ten $7 \mathrm{e}$ vallen. Het hof had deze paintballmarkers vanwege de sprekende gelijkenis als wapens aangemerkt. In cassatie werd dit bestreden. De Hoge Raad oordeelde dat dit bezwaar niet eerst in cassatie naar voren kan worden gebracht, nu de verdediging zich bij de feitenrechters had beperkt tot een beroep op dwaling. Dat beroep was naar het oordeel van de Hoge Raad op goede gronden verworpen.

27. Namelijk: een uitsparing in het huis van een luchtdrukgeweer die een hulsuitwerpvenster moet voorstellen, een pseudovuurselector en een pseudopatroonhouder. stelling via categorie I ten 7e uitzondert. ${ }^{28}$ Een verdere verbleking is het gevolg van de implementatie van de De-activeringsrichtlijn. ${ }^{29}$ Tot voor kort konden alleen bepaalde vuurwapens (de basculerende en grendelgeweren) formeel onbruikbaar worden gemaakt, nu kan elk vuurwapen (met uitzondering van kanonnen) zodanig onklaar worden gemaakt dat het onder de vrijstelling van artikel 18 RWM komt te vallen. En door die vrijstelling kan geen sprake (meer) zijn van een voorwerp dat door de sprekende gelijkenis onder artikel 2 WWM valt. Blijft over de strafbaarheid van voorwerpen die zijn aangewezen omdat zij een (zodanig) ernstige bedreiging van personen kunnen vormen dat zij onder categorie I moeten vallen. Daarmee zou categorie I ten 7e als vangnetbepaling te billijken zijn. Maar niet langer meer voor de voorwerpen met een sprekende gelijkenis. Is dit nu allemaal zo erg? Welnee: wie een lookalike vuurwapen bezit, mag daarmee blij zijn. Kwalijk is als het nepvoorwerp voor bedreiging wordt gebruikt, maar dat levert strafrechtelijk voldoende op voor verdenking ter zake artikel $285 \mathrm{Sr}$, terwijl het voorwerp onder die omstandigheden onder categorie IV ten 7e valt.

De slotconclusie kan kort zijn: speelgoed dat sprekend op een Kalasjnikov AK 47 lijkt is toegestaan; zelfs het voorhanden hebben van de echte $A K 47$ mag, mits dit vuurwapen volgens de regels werd dichtgelast. Maar over luchtdrukwapens doen we moeilijk. Achteraf moeten alle credits naar justitieminister Scholten gaan, die in 1963 voorstelde om een Wet op de luchtdrukwapens te maken. Deze minister, zoon van de befaamde hoogleraar (Paul) Scholten, heeft dat niet voor elkaar gekregen. Het had zijn legislatieve erfenis (bestaande uit de Monumentenwet en de Archiefwet) niet misstaan.
28. De implementatie van Richtlijn 2009/28/EG had een wijziging van artikel 3 RWM tot gevolg, Stcrt. 2014, 18098.

29. Uitvoeringsverordening (EU) 2015/2403, met wijziging van artikel 18 RWM, Stcrt. 2016, 26810. 